\title{
Precision conservation: A geospatial decision support tool for optimizing conservation and profitability in agricultural landscapes
}

\author{
M. McConnell and L.W. Burger
}

\begin{abstract}
The USDA Farm Bill conservation programs provide landowner incentives to remove less productive and environmentally sensitive lands from agricultural production and reestablish them in natural vegetation (e.g., native grasses, trees, etc.) to achieve conservation objectives. However, removal of arable land from production imposes an opportunity cost associated with loss in revenue from commodities that otherwise would have been produced. Recent Farm Bills have increasingly emphasized targeted practices to achieve specific environmental outcomes that maximize environmental benefits relative to cost. The Habitat Buffers for Upland Birds practice (CP-33) under the continuous Conservation Reserve Program is an example of a targeted conservation practice that has produced measureable outcomes (increased bobwhite and grassland bird populations) with relatively minor changes in primary land use. However, establishing conservation buffers on profitable farmland may be incompatible with the economic objectives of landowners/producers. Precision agriculture technologies provide a powerful conservation planning tool for identifying environmental and economic opportunities in agricultural systems. Precision implementation of conservation practices, such as $\mathrm{CP}-33$, is the foundation of strategic conservation planning and is essential for optimization of environmental and economic benefits. Toward this end, we developed a geospatial decision support tool (Arc GIS tool) to inform this decision-making process. We illustrate the geoprocessing workflow of the tool and demonstrate the conditions under which precision implementation of conservation practices can concomitantly increase whole-field profitability and environmental services for an example farm in Mississippi.
\end{abstract}

Key words: conservation buffers—geospatial—profitability—spatially explicit

\begin{abstract}
Agriculture dominates human land use (Robertson and Swinton 2005) and influences the environmental goods and services produced by agroecosystems. In the United States, 50\% (382.8 million ha $[945,919,400.26 \mathrm{ac}])$ of the contiguous 48 states is devoted to cropping or grazing land uses (USDA 2003). With exponential human population growth (Lutz et al. 2001; United Nations Population Division 2002) and associated increases in food demand (Bongaarts 1996), production agriculture continues to intensify, favoring mass production of food and fiber resources (Tilman et al. 2002). To meet global demands and remain competitive in global markets, modern agriculture emphasizes maximizing productivity (e.g.,
\end{abstract}

costs and environmental impacts in a spatially explicit manner (Stull et al. 2004).

One goal of PA is to efficiently allocate inputs so as to maximize yield $\left(\mathrm{t} \mathrm{ha}^{-1}\right)$ and/or profitability $\left(\$ \mathrm{ha}^{-1}\right)$. When yield is maximized, the amount of land needed to meet food demands is reduced. If production and revenue targets can be met with less cropped acreage, the opportunity for land reallocation is created. Less productive (i.e., those with reduced yields or lower profitability) and environmentally sensitive agricultural lands are logical candidates for conservation implementation or alternative land use (i.e., biofuels production) (Tilman et al. 2002). Conservation and food production goals can be linked through increasing yield on cultivated land, thereby freeing up land for conservation use (Green et al. 2005). Precision agriculture can increase profitability for producers, while potentially enhancing environmental services of agricultural systems and societal benefits (Zhang et al. 2000). Although adoption of PA technologies has been increasing since the early 1990s (Daberkow and McBride 2003), its applications for conservation planning have, until recently, been widely overlooked (Lowenberg-DeBoer 1996; Stafford 2000).

The emerging field of precision conservation uses PA tools to achieve conservation objectives. Precision conservation (PC) is defined as "a set of spatial technologies and procedures linked to mapped variables directed to implement conservation management practices that take into account spatial and temporal variability across natural and agricultural systems" (Berry et al. 2003). Much like PA, PC is dependent on geospatial tools, such as global positioning systems (GPS), geographic information systems, digital landscape information, spatially explicit mathematical models, and intensive computer analysis (Dosskey et al. 2005). Prior research on PC's application in conservation planning have generally focused on nutrient loading and/or erosion control (Berry et al. 2003; Dosskey et al. 2005; Kitchen et al. 2005). Precision conservation has also been used in strategic establishment of conserva-

Mark Mcconnell is a graduate student and L. Wes Burger is a professor of Wildlife Ecology and Management at Mississippi State University and is associate director of Agriculture and Natural Resources at the Geosystems Research Institute, Mississippi State, Mississippi. 
tion buffers to reduce nutrient runoff and topsoil erosion (Stull et al. 2004; Dosskey et al. 2005) and has been shown to increase buffer effectiveness; however, few examples of the use of PAs or PCs for wildlife conservation planning exist.

Agricultural producers operate under uncertainty created by environmental and market stochasticity. Consequently, financial concerns strongly influence producer decisions (Kitchen et al. 2005). Variations in global economies, commodity prices, agricultural policies (e.g., Farm Bill, trade agreements), subsidy payments, weather/climatic events, input costs, and equipment expenses together influence risk and profitability for landowners and producers. Removing land from production for conservation imposes an opportunity cost associated with loss in revenue from commodities that otherwise would have been produced (USDA 2003). "Conservation must be compatible with profitability" (Kitchen et al. 2005). To make conservation implementation economically attractive to agricultural landowners, conservation programs must address economic concerns of producers (USDA 2003). Conservation and profitability can coexist if both ecological and economic demands are taken into account (Holzkamper and Seppelt 2006).

Farm policy in the United States, as codified in the Farm Bill and implemented through commodity and conservation programs, has evolved to recognize the importance of financial concerns and profitability in the adoption of conservation practices. Consequently, conservation programs provide financial incentives to offset both the direct and opportunity costs of conservation practice adoption.

Conservation buffers represent a suite of best management practices designed to take the most environmentally sensitive lands out of production and address specific resource concerns (e.g., soil erosion, water quality, wildlife conservation) in a manner that is compatible with row crop production systems while removing the least amount of ground from production. These targeted conservation practices often carry extra economic incentives (i.e., signup incentive payments, increased cost-share, elevated rental rates) to induce adoption. To increase the degree of targeting, eligibility of cropland for conservation buffer practices is constrained based on spatial relationships, such as hill slope position, proximity to water bodies

\section{Figure 1}

The study site was a 1,200 ha row crop production farm in Tallahatchie County, Mississippi, United States.

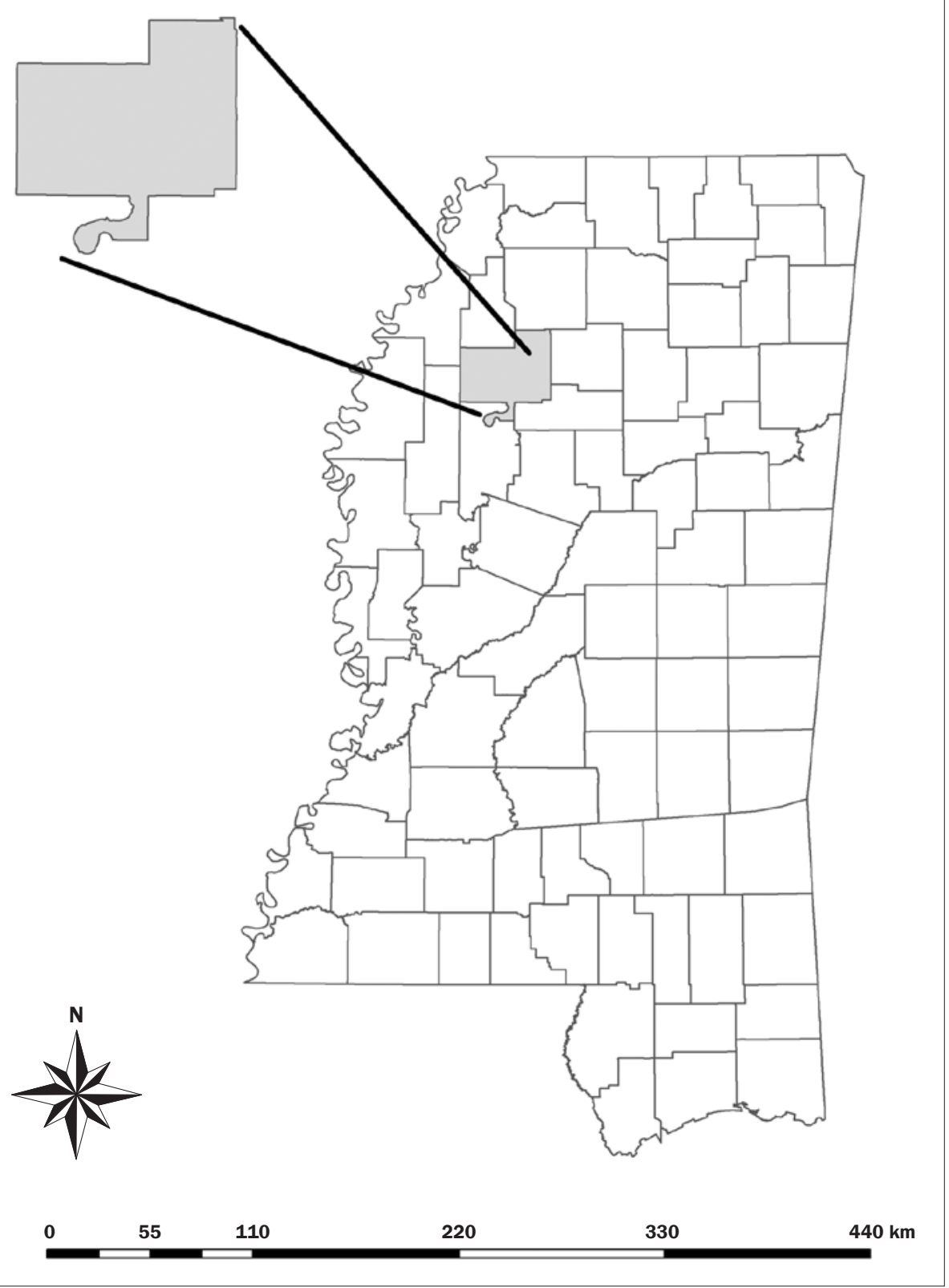

and wetlands, proximity to field margins, or other ecologically sensitive features. Buffer width, configuration, and plant materials are constrained so as to achieve desired resource outcomes. However, enrollment of all eligible land might not necessarily maximize financial returns, and thus might not be the best land use from a profitability standpoint. A strategic enrollment that maximizes conservation benefits, subject to the constraint that economic benefits equal or exceed that under agricultural production might be con- sidered optimal from a producer standpoint and might increase adoption.

Effective implementation of PC will require computation and analysis of spatially explicit field-level information to identify both enrollment opportunities (eligibility criteria) and spatial variation in profit under production versus alternative enrollment strategies. However, few agricultural producers possess the geospatial processing skill required to conduct even rudimentary analyses. Decision support tools (DST) can assist producers in making informed decisions 
regarding tradeoffs between production and conservation enrollments. However, to date, no DST exists to assist producers in comparing profitability of crop production with conservation program enrollment in a spatially explicit context.

In this study, we describe a geospatial DST that identifies spatially explicit conservation program opportunities and characterizes economic tradeoffs of conservation program participation versus agricultural production. We illustrate the utility of this tool on a 1,200 ha $(\sim 2,965 \mathrm{ac})$ row crop production farm in Tallahatchie County, Mississippi, United States (figure 1). Twelve production fields were chosen from this farm based on availability of spatially explicit yield data. We present the geoprocessing steps for identifying conservation and economic opportunities and provide an example of the economic benefits of conservation enrollment created by this decision support tool at the farm and field levels. We use conservation buffer practices as an example to illustrate the ability of the tool to provide economic information to inform the decision-making process. This tool will provide agricultural producers and natural resources professionals with the data needed to make informed land management decisions that optimize their specific goals.

\section{Materials and Methods}

Our geospatial decision support tool is designed to operate as a script or an extension in ArcGIS (ArcInfo version 9.3.1) software. It was coded in Python to ensure forward compatibility with ArcGIS version 10x. The tool consists of two distinct modules: (1) to define practice-specific eligibility for two conservation buffer practices and (2) to construct profit surfaces from spatially explicit yield data and compare profitability under production versus alternative buffer enrollments. To illustrate conservation opportunities and economic tradeoffs we chose a candidate set of conservation buffer practices and ran simulation models to identify their eligibility on a production agriculture farm in Tallahatchie County, Mississippi, United States.

Eligibility Tool. The programmatic vehicle for implementing conservation buffers has been the Continuous Conservation Reserve Program (CCRP), under the conservation title of the Farm Bill. Under CCRP, a variety of conservation buffer practices (i.e., filter strips, riparian forest buffers, field borders, and upland habitat buffers) are available to accom- plish specific resource conservation objectives associated with national conservation initiatives. Each conservation practice has a unique set of eligibility criteria and financial incentives associated with its adoption. Therefore, our tool first identifies those regions of an agricultural field where a particular practice is eligible, based on spatial relationships.

Multiple inputs are required to quantify eligibility for each practice contingent on its specific resource objective. We used Conservation Practice 21 (CP-21 Filter Strips) and Conservation Practice 33 (CP-33 Habitat Buffers for Upland Birds) to illustrate how this tool identifies conservation opportunities.

All fields must meet a feasibility to crop and cropping history criterion as defined in the current Farm Bill (four of the six years 1996 to 2001 under the 2002 Farm Bill, 2002 to 2007 under the 2008 Farm Bill) Once these criteria are met, implementation of a conservation practice on a particular field is a function of the practice-specific eligibility criteria. Filter strips enrolled under CP-21 must be adjacent and parallel to a wetland or water body (e.g., streams, lakes, wetlands, sinkholes, etc). The portion of the field within $36.5 \mathrm{~m}$ (120 ft) of the edge of the wetland is eligible for enrollment in CP-21 (USDA FSA 2005). Minimum average buffer

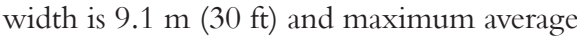
buffer width is 120 for CP-21. Whereas filter strips and riparian forest buffers are typically on the downslope side of a field, upland habitat buffers can be established around the entire field boundary. Average buffer width must be between 30 and $120 \mathrm{ft}$ (USDA FSA 2005).

Defining spatially explicit practice eligibility requires a set of user-provided spatial data layers. Required spatial data layer inputs include (1) hydrography, (2) field boundaries, (3) digital soil maps, and (4) county and soil specific Conservation Reserve Program rental rates. To maximize the breadth of applicability, we have designed the tool to use the National Hydrography Dataset (NHD), USDA Farm Service Agency's common land unit field boundaries, and Soil Survey Geographic database. The NHD layers are a set of digital vector files that map features, such as lakes, ponds, streams, rivers, and wetlands, and can be accessed via the United States Geological Service (2009). Common land unit data layers are vector files that spatially define farm field boundaries and are available via landowner consent from Farm
Service Agency county offices. Field boundaries are defined as "agricultural land that is delineated by natural and manmade boundaries, such as roadways, tree lines, waterways, fence lines, etc." (USDA FSA 2005). County and soil-specific Conservation Reserve Program rental rates (SRR) represent the cash value of agricultural land based on county-specific soil type, which is gauged by soil type productivity, and are available for download from the USDA Farm Service Agency Soils Data Management System (USDA FSA 2009). These SRR can be entered into a spreadsheet and spatially joined (attributes correspond to a spatial location) to the soils layer in ArcMap (ESRI 2009). Users may substitute user-developed layers with appropriate geometry and attributes (e.g., field boundaries) for any of these inputs by pointing the tool to the appropriate patch and file name.

Under CCRP, eligible cropland must be adjacent and parallel to a perennial or seasonal stream, sinkhole, wetland, or other permanent water body (USDA FSA 2005). Seasonal streams are defined "as a stream that contains water for only part of the year but more than just during and/or after rainfall of snowmelt" (USDA FSA 2005). Wetlands, under CCRP, include permanently flooded, intermittently exposed, semipermanently flooded and seasonally flooded wetlands (USDA FSA 2005). The USDA Natural Resources Conservation Service conservation planners typically use a combination of NHD layers, US Geological Survey topographic maps, and field inspections to define eligible wetlands. The NHD layers serve as the base digital layers for planning but will likely require user modification based on site inspection and current aerial imagery to updated conditions where drainage modification has occurred.

Once required inputs are obtained, the tool performs a series of geoprocessing steps to spatially define the regions of practicespecific eligibility within the planning extent. For simplicity, the tool is designed to output eligible field regions for one conservation practice at a time. These practice-specific eligible regions are output as a shapefile and are illustrated in the view window on a georeferenced aerial photograph, which can be downloaded from the USDA Natural Resources Conservation Service Geospatial Data Gateway (USDA NRCS 2008). We will describe the conceptual framework of this process acknowledging that the process 
will change for each practice based on eligibility criteria. To model these parameters in spatially explicit context, we use ArcGIS (ArcInfo version 9.3.1) software.

The Eligibility Tool will perform six major functions:

1. Identify and buffer all eligible boundary layers (field boundaries and/or water bodies) within the geographic extent (e.g., farm boundary) by the maximum width for that practice

2. Combine eligible buffers into one buffer feature layer

3. Intersect the buffer feature layer with the soils layer

4. Calculate the weighted SRR for each buffer based on three most prevalent soils

5. Calculate the area for each buffer

6. Output the single part, multiple feature buffer layer with buffer specific area and weighted SRR

Profitability Tool. Several inputs and geoprocessing steps are required to calculate profitability of agricultural fields. The most essential element is spatially explicit yield data. Yield data is obtained from GPS yield monitors. Data obtained from GPS yield monitors affixed to combines is typically in a proprietary format chosen by the manufacturer (e.g., John Deere, AgLeader). During harvest, data is usually collected and stored on a memory device. Such devices can be removed from the in-cab device and uploaded to a personal computer with yield editing software, such as Yield Editor or SMS Basic. Data imported to such software can easily be exported to a shapefile and uploaded in a Geographic Information System (e.g., ArcMap). Yield data is typically downloaded from memory cards and calibrated to dry yield, then passed through a series of filtering steps to eliminate erroneous data points commonly associated with GPS yield monitors such as grain flow delay, time delays, rapid velocity changes, positing errors, etc. (Sudduth and Drummond 2007). Cleaned yield data is then exported as a shapefile.

In addition to yield data, economic information about each conservation practice is necessary to calculate profitability under alternative buffer scenarios. Buffer practices under the CCRP typically include a Signup Incentive Payment, Practice Incentive Payment, cost share assistance, and county and soil-specific SRR. Together these values, minus any incurred costs (i.e., maintenance costs), account for total buffer revenue. Payment costs are amortized over the 10-year contract to produce annual per acre costs and revenues.

Agricultural producers understand that they often experience yield reductions at field margins. These reductions are due to a combination of factors including production practices (field traffic causing compaction), variable inputs (herbicide, fertilizer, etc.), greater weed and insect pressure, and competition with adjacent vegetation for sunlight, water, and nutrients. Conservation buffers have been shown to have a negligible effect on adjacent crop yield (Barbour 2006; Stamps et al. 2008). Furthermore, the implementation of conservation buffers in low-yielding crop margins does not simply displace a preexisting yield reduction associated with field margins (Stamps et al. 2008). Barbour (2006) also found that in circumstances where yield was reduced next to a conservation buffer that the magnitude of reduction was small enough to be offset by the economic gain associated with conservation buffer payments (e.g., SRR and Signup Incentive Payment). Yield data is useful for identifying field regions with reduced productivity. Converting yield data into a spatially explicit profitability map (i.e., profit surface) is more useful because it illustrates where revenue is gained or lost. Once calibrated and cleaned, the yield data can be imported into the DST, where the necessary attributes and calculations will be carried out.

The Profitability Tool will perform five preliminary functions:

1. Create six attribute fields: Commodity Price, Gross Revenue, Government Payments, Total Revenue, Production Costs, Net Revenue

2. Assign and calculate values for each field a. Commodity Price $=$ [User Input $]$

b. Gross Revenue $=$ [Commodity Price $\times$ Yield]

c. Government Payments $=$ [User Input]

d. Total Revenue $=[$ Gross Revenue

+ Government Payments]

e. Production Costs $=$ [User Input $]$

f. $\quad$ Net Revenue $=[$ Total Revenue Production Costs]

3. Interpolate yield data by Ordinary Kriging method using the Net Revenue Field to generate profit surface

4. Calculate mean Net Revenue (i.e., profitability) using zonal statistics to generate whole-field profitability under production alone

5. Export profit map
We recognize that such parameters as commodity price, costs, and SRR are subject to stochasticity associated with agricultural market conditions, Farm Bill provisions, and trade agreements. This Profitability Tool is designed to model a range of values for all parameters. Therefore, this tool can easily be used to model the financial opportunities of conservation buffer enrollment across a range of commodity prices to better inform the decision-making process of conservation enrollment. For example, McConnell (2011) modeled the effects of CP-33 on field profitability on 34 agricultural fields in Mississippi across a range of commodity prices and found that opportunities for financial gain through CP-33 enrollment exist even at high commodity prices.

Calculating whole-field profitability under agricultural production alone identifies field regions where revenue is lost (i.e., negative net revenue) or minimal, whereas, calculating whole-field profitability under alternative conservation buffer enrollments identifies field regions where profitability under conservation enrollment is greater than that of production alone. Running this analysis independently for multiple conservation practices and alternative enrollments within a practice provides a multitude of land-use options for agricultural producers.

The Profitability Tool will then perform six final functions:

1. Create alternative width buffer polygons adjacent to eligible boundary layers (field boundaries and/or water bodies)

2. Add practice-specific financial incentives to previously calculated weighted SRR to generate the Buffer Revenue Field

3. Convert the buffer layer to a raster using the Buffer Revenue Field

4. Replace the buffer region from previously created profit surface with a newly created buffer layer using Raster Calculator

5. Calculate the mean Net Revenue (i.e., profitability) using zonal statistics to generate whole-field profitability under each buffer scenario

6. Export a profit map

7. Calculate the difference in profit for alternative buffer widths relative to full production

\section{Results and Discussion}

Eligibility Tool. On the example Tallahatchie County farm, the tool identified 307 ha $(\sim 758 \mathrm{ac})$ of eligible land for 
CP-33 and 104 ha ( 260 ac) eligible for CP-21 (figures 2 and 3). This information provides land managers and producers with a thorough understanding and visualization of how and where conservation opportunities exist on the landscape. While noteworthy, this estimate only reflects the conservation opportunity and not the economic opportunity. It is important to note that not all land eligible for conservation is more profitable under conservation enrollment compared to agricultural production. The need for economic analysis is essential for effective conservation enrollment.

Our research demonstrates the utility and effectiveness of PA technologies coupled with a geospatial DST to identify conservation opportunities in agricultural landscapes. Quantifying conservation eligibility is paramount because most producers and natural resource planners cannot visualize where and how conservation programs fit into their production systems. Illustrating eligible land for multiple conservation practices provides options for producers to optimize not only their economic interests but also their specific natural resource concerns (i.e., water quality, soil loss, wildlife habitat). The use of geospatial technology is essential to this process, and our DST produces simple, spatially explicit maps that producers can use to inform land-use decisions.

Profitability Tool. Our tool uses PA technology to identify economic opportunities in agricultural fields. Spatially explicit profit maps are generated to visualize the monetary distribution of agricultural production alone (figures 4 and 5). Simple calculations are then done to compare profitability of production alone to one of many conservation scenarios (figures 6 and 7). Clearly, year-specific profitability does not capture the full range of spatial and temporal variation associated with stochastic environmental conditions and crop rotations. Spatially explicit profit surfaces can be averaged over multiple years to better inform decision making.

Figures 8 and 9 illustrate how conservation buffers can be used to increase whole-field profitability by removing marginal land from production and enrolling it in a conservation practice. It is important to note that not all fields experience yield reductions near field margins at a magnitude that would justify conservation enrollment. However, across an entire farm, this process can be instrumental at increasing total revenue if applied strategically (conservation only where profitable).

Identifying eligible field regions where revenue from conservation enrollment exceeds that of agricultural production on a cell by cell basis requires a simple manipulation to the profit surface. Although the profit surface itself illustrates the profitability value of each cell in the field, there are often too many cells with individual values to discern any reliable patterns. However, by simply altering the scale of the profit surface to reflect those values above and below the calculated SRR, users can identify those field regions where profitability under agricultural production is less than that of the SRR - thereby concluding which eligible field regions would be more profitable under conservation enrollment (figure 10).

Our analysis illustrates the utility of this tool to provide economic information that can be used to make informed land management decisions. Across the range of fields and crop types in the analysis, it is clear that some amount of CP-33 enrollment is always economically beneficial (figures 11 and 12) for this particular farm. However, the premise of this tool is that decisions can, and should, be made at the field level (i.e., targeted conservation). Hence our analysis of individual fields indicates that conservation enrolment (e.g., CP-33), can be economically beneficial across a range of buffer widths. For example, in the soybean field, a buffer enrollment of $27.4 \mathrm{~m}$ generated the greatest financial return, whereas on the corn field, financial return peaked at $9.1 \mathrm{~m}$ and then declined. Such information can then be used to make informed decisions about conservation enrollment on those fields without jeopardizing profitability. Although the magnitude of increase in profitability varied substantially at the field and farm levels, some CP-33 enrollment increased field revenue in each field. Therefore, the economic effects of conservation buffer enrollment should be viewed as an ancillary benefit to a responsible land management decision.

\section{Summary and Conclusions}

Traditionally conservation implementation in agricultural landscapes has often been perceived to hinder or directly reduce profitability. However, as financial incentives increase in scope, quantity, and specificity, strategic enrollment in conservation programs can actually increase profitability.
The key to realizing the potential in these programmatic opportunities is helping producers visualize spatially explicit economic and environmental tradeoffs. Precision agriculture technology used in a PC framework can help to optimize both profitability and environmental benefits. Although most producers desire to be good stewards of natural resources and value environmental services that their land produces, economic constraints often hinder adoption. Natural resources professionals must find innovative solutions that balance environmental and economic tradeoffs. Precision conservation provides the necessary tools to implement profitable conservation in a spatially explicit framework that optimizes financial returns for the producer. Our research provides a geospatial DST that identifies conservation and economic opportunities in agricultural landscapes and evaluates the economic tradeoffs of conservation enrollment versus agricultural production. This tool can aid in achieving landscape- or watershed-level conservation goals by increasing adoption of conservation practices.

\section{Acknowledgements}

This research was primarily funded by a USDA National Institute of Food and Agriculture Agriculture and Food Research Initiative special research grant through the Geosystems Research Institute's New Satellite and ComputerBased Technology for Agriculture, Master's project. Additional support came from the Forest and Wildlife Research Center and Department of Wildlife, Fisheries and Aquaculture at Mississippi State University. We thank landowners and crop consultants who collected and provided yield data in addition to providing expertise in the field of PA.

\section{References}

Baligar, V.C., N.K. Fageria, and D.I. He. 2001. Nutrient use efficiency in plants. Communications in Soil Science and Plant Analysis 32:921-950.

Barbour, P.J. 2006. Ecological and economic effects of field borders in row crop agriculture production systems in Mississippi. PhD Dissertation, Mississippi State University, Mississippi.

Berry, J.K., J.A. Delgado, R. Khosla, and FJ. Pierce. 2003 Precision conservation for environmental sustainability. Journal of Soil and Water Conservation 58(6):332-339.

Bongaarts, J. 1996. Population Pressure and the Food Supply System in the Developing World. Population and Development Review 22:483-503.

Daberkow, S.G., and W.D. McBride. 2003. Farm and operator characteristics affecting awareness and adoption of precision agriculture technologies in the US. Precision Agriculture 4:163-177. 


\section{Figure 2}

Total eligible area (307 ha) for Conservation Practice 33 (CP-33) Habitat Buffers for Upland Birds on a 1,200 ha grain farm in Tallahatchie County, Mississippi, United States.
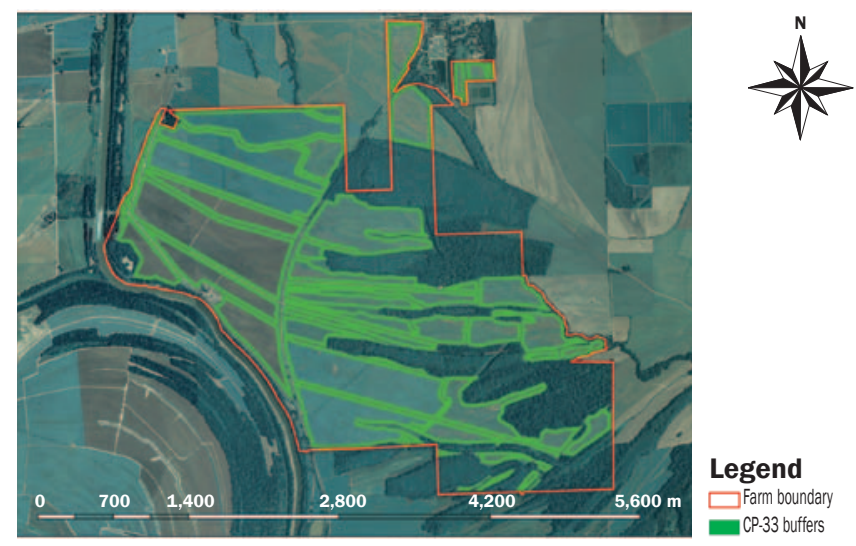

\section{Figure 4}

Profit surface for a center-pivot irrigated soybean field, assuming a $\$ 331 \mathrm{t}^{-1}$ commodity price and a $\$ 597.87 \mathrm{ha}^{-1}$ production cost in Tallahatchie County, Mississippi, United States.

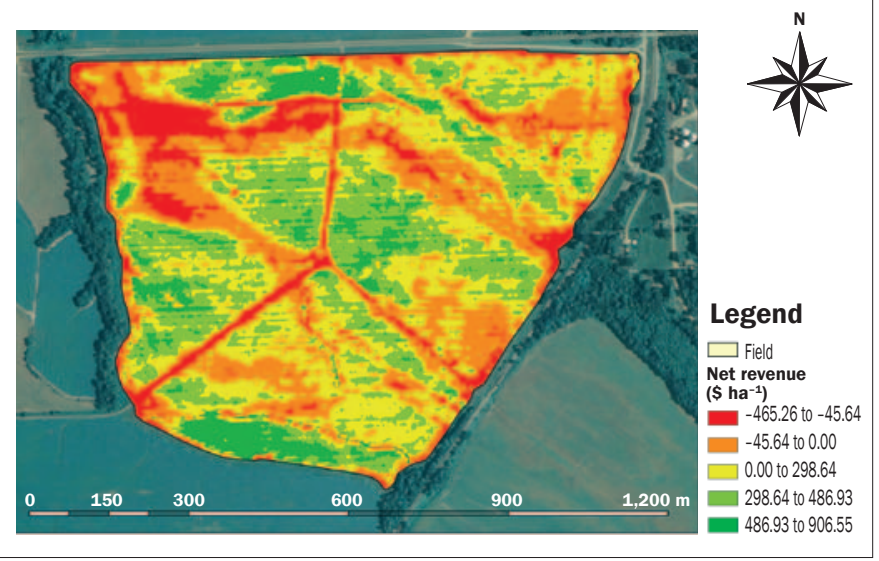

\section{Figure 6}

Profit surfaces for alternative Conservation Practice 33 (CP-33) buffer widths on a center-pivot irrigated soybean field in Tallahatchie County, Mississippi, United States: (a) 9.1 m CP-33 buffer, (b) $18.2 \mathrm{~m}$ CP-33 buffer, (c) $27.4 \mathrm{~m} \mathrm{CP-33}$ buffer, and (d) $36.5 \mathrm{~m} \mathrm{CP-33}$ buffer. (a)

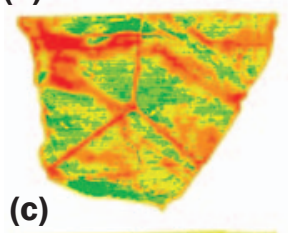

(c)

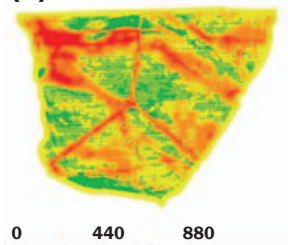

(b)

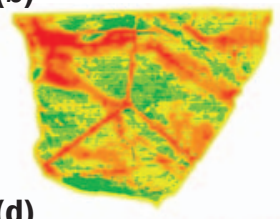

(d)

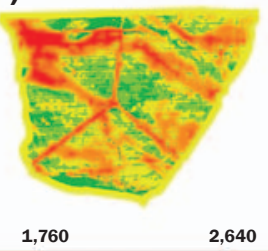

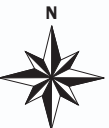

Legend

Net revenue

\$ ha ${ }^{-1}$

-465.26 to -29.507

-29.507 to 0.00

$\square .00$ to 309.40

309.40 to 497.69

$\begin{array}{r}397.69 \text { to } 906.55 \\ \hline\end{array}$

\section{Figure 3}

Total eligible area (104 ha) for Conservation Practice 21 (CP-21) Filter Strips on a 1,200 ha grain farm in Tallahatchie County, Mississippi, United States.

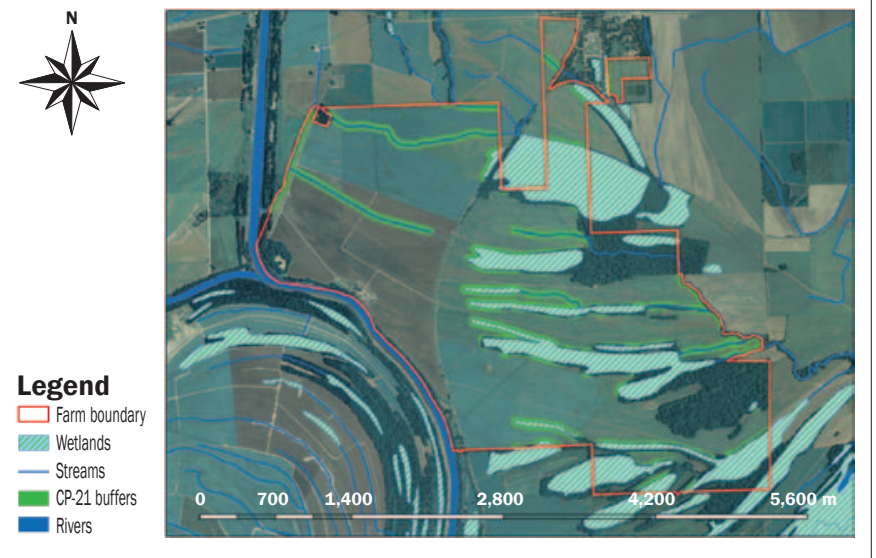

\section{Figure 5}

Profit surface for a center-pivot irrigated corn field, assuming a $\$ 138 \mathrm{t}^{-1}$ commodity price and a $\$ 1,237.53 \mathrm{ha}^{-1}$ production cost in Tallahatchie County, Mississippi, United States.

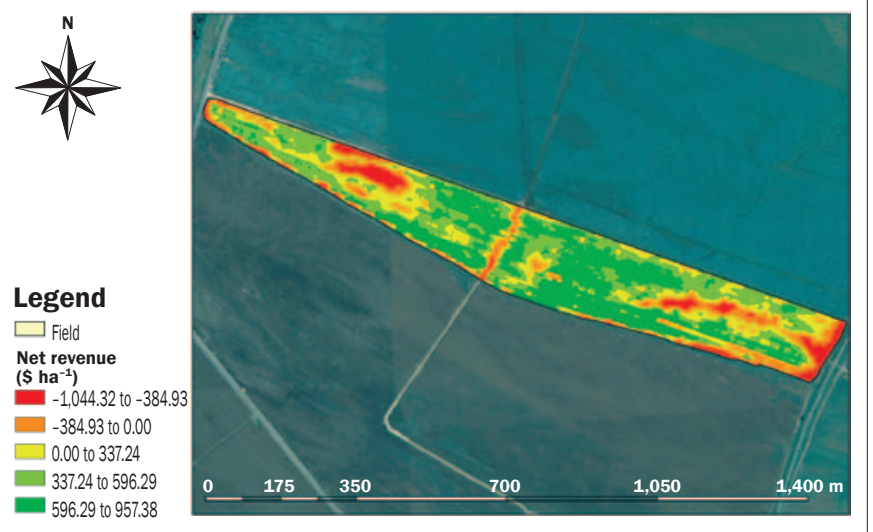

\section{Figure 7}

Profit surfaces for alternative Conservation Practice 33 (CP-33) buffer widths on a center-pivot irrigated corn field in Tallahatchie County, Mississippi, United States: (a) 9.1 m CP-33 buffer, (b) $18.2 \mathrm{~m} \mathrm{CP-33}$ buffer, (c) $27.4 \mathrm{~m} \mathrm{CP-33}$ buffer, and (d) $36.5 \mathrm{~m} \mathrm{CP}-33$ buffer.

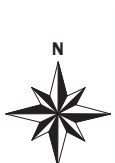

(a)

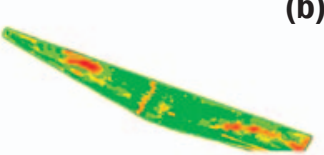

(b)

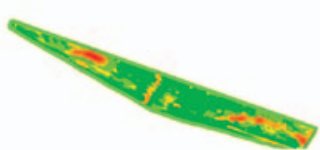

(c)

Legend

Net revenue

( $\$$ ha $^{-1}$ )

$-1,038.90$ to -428.27

-428.27 to -83.81

-83.81 to 0.00

0.00 to 479.84

479.84 to 957.38

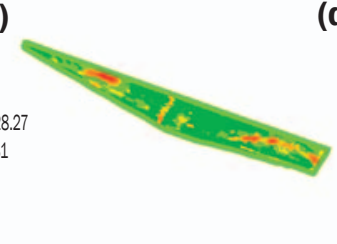

(d)

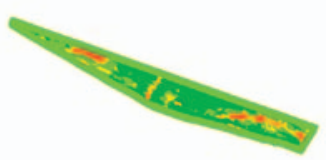

$420 \quad 840$

1,680

2,520 3,360 


\section{Figure 8}

Whole-field net revenue of alternative Conservation Practice 33 buffer widths on a center-pivot irrigated corn field in Tallahatchie County, Mississippi, United States (mean yield = 11.19 MT ha ${ }^{-1}$; commodity price $\left.=\$ 138 \mathrm{t}^{-1}\right)$.

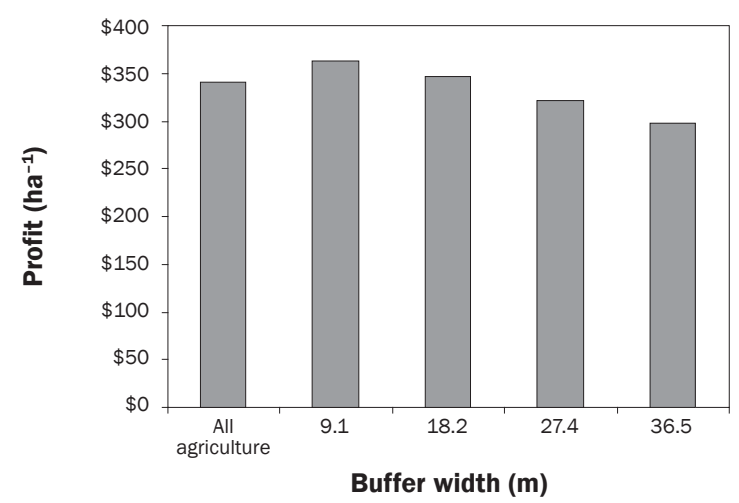

\section{Figure 10}

Adjusted profit surface for a center-pivot irrigated soybean field in Tallahatchie County, Mississippi, United States.

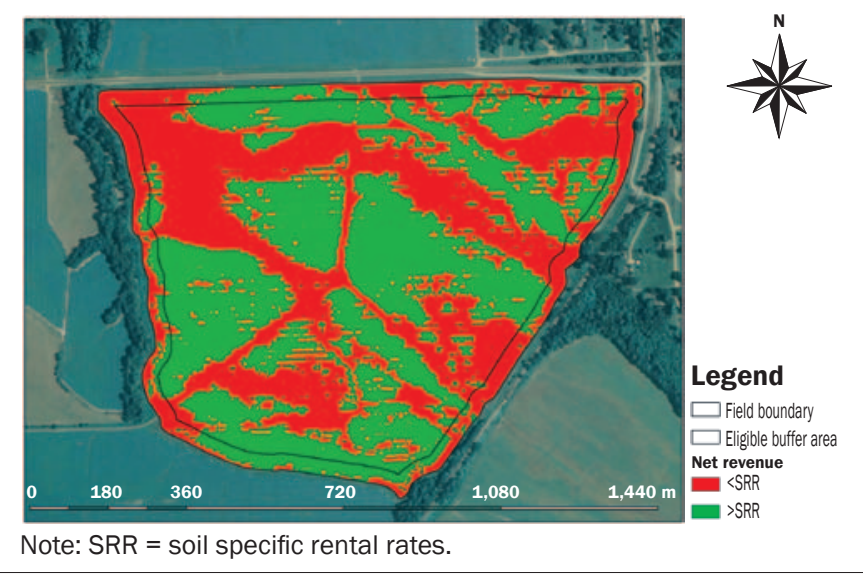

\section{Figure 9}

Average whole-field net revenue of alternative Conservation Practice 33 buffer widths on a center-pivot irrigated soybean field in Tallahatchie County, Mississippi, United States (mean yield = 2.32 MT ha $^{-1}$; commodity price $=\$ 331 \mathrm{t}^{-1}$ ).

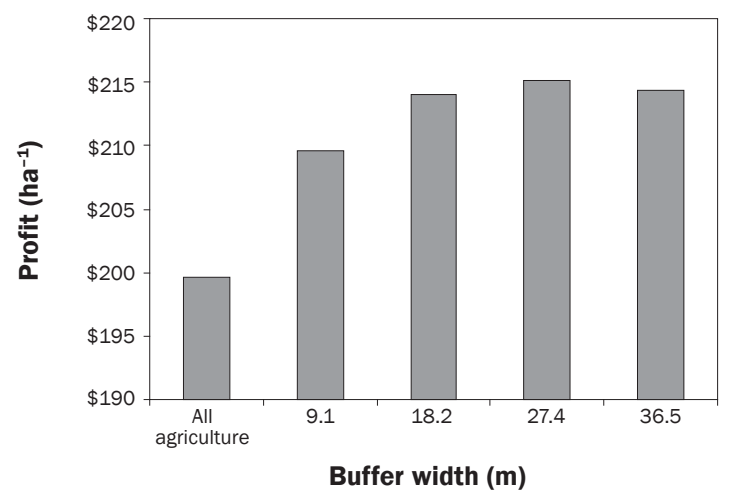

\section{Figure 11}

Average whole-field net revenue $( \pm \mathrm{se})$ of alternative Conservation Practice 33 buffer widths across multiple soybean fields $(n=7)$ in Tallahatchie County, Mississippi, United States (commodity price $=$ \$331 $\mathrm{MT}^{-1}$ ).

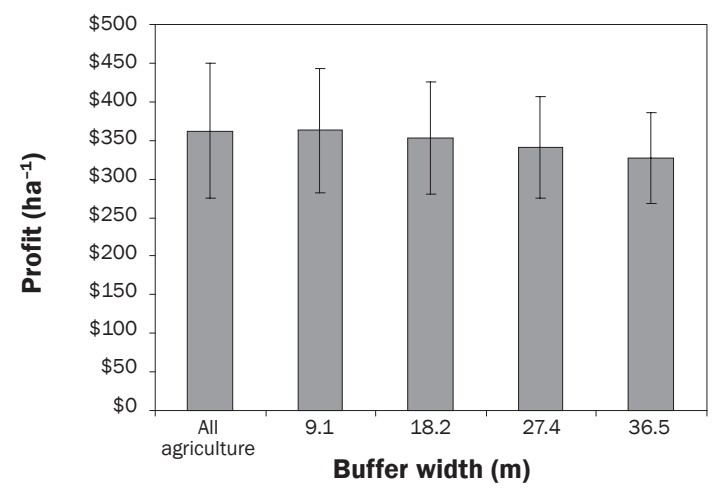

\section{Figure 12}

Average whole-field net revenue ( \pm se) of alternative Conservation Practice 33 buffer widths across multiple corn fields $(n=5)$ in Tallahatchie County, Mississippi, United States (commodity price $=$ \$138 MT ${ }^{-1}$ ).

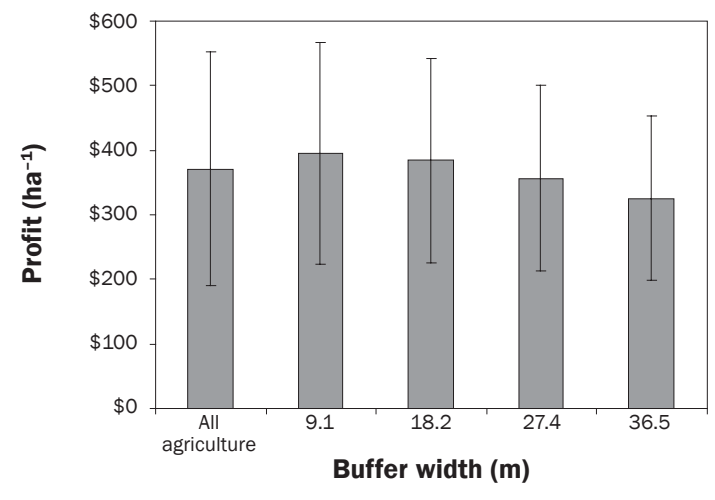


Dosskey, M.G., D.E. Eisenhauer, and M.J. Helmers. 2005. Establishing conservation buffers using precision information. Journal of Soil and Water Conservation 60(6):349-354.

ESRI (Environmental Systems Resource Institute). 2009. ArcMap 9.3.1 ESRI, Redlands, California.

Green, R.E., S.J. Cornell, J.P.W. Scharlemann, and A. Balmford. 2005. Farming and the Fate of Wild Nature. Science 307:550-555.

Holzkamper, A., and R. Seppelt. 2006. Evaluating costeffectiveness of conservation management actions in an agricultural landscape on a regional scale. Biological Conservation 136:117-127.

Kitchen, N.R., K.A. Sudduth, D.B. Myers, R.E. Massey, E.J. Sadler, R.N. Lerch, J.W. Hummel, and H.L. Palm. 2005. Development of a conservation-oriented precision agriculture system: Crop production assessment and plan implementation. Journal of Soil and Water Conservation $60(6): 421-430$.

Lal, R. 2000. A modest proposal for the year 2001: We can control greenhouse gases and feed the world... with proper soil management. Journal of Soil and Water Conservation 55(4):429-433.

Lowenberg-DeBoer,J.1996. Economics of precision farming: Payoff in the future. Purdue University, IN. http:// pasture.-ecn.purdue.edu/ mmorgan/PFI/pfiecon.html.

Lutz, W., W. Sanderson, and S. Scherbov. 2004. The end of human population growth in the 21st century: New challenges for human capitol formation and sustainable development. London, United Kingdom: Earthscan.

McConnell, M.D. 2011. Using precision agriculture technology to evaluate the environmental and economic tradeoffs of alternative CP-33 enrollments. Thesis, Mississippi State University, Starkville, USA.

Robertson, G.P., and S.M. Swinton. 2005. Reconciling agricultural productivity and environmental integrity: A grand challenge for agriculture. Frontiers in Agriculture and the Environment 3:38-46.

Stafford, J.V. 2000. Implementing precision agriculture in the 21st century. Journal of Agriculture Engineering Research 76:267-275.

Stamps, W.T., T.V. Dailey, N.M. Gruehhagen, and M.J. Linit. 2008. Soybean yield and resource conservation field borders. Agriculture, Ecosystems, and Environment 124:142-146.

Stull, J., C. Dillon, S. Shearer, and S. Isaacs. 2004. Using precision agriculture technology for economically optimal strategic decisions: The case of CRP filter strip enrollment. Journal of Sustainable Agriculture 24:79-96.

Sudduth, K.A., and S.T. Drummond. 2007. Yield editor: Software for removing errors from crop yield maps. Agronomy Journal 99:1471-1482.

Tilman, D., D.G. Cassman, P.A. Matson, and S. Polasky. 2002. Agriculture sustainability and intensive production practices. Nature 418:671-677.
USDA. 2003. Natural Resource Inventory. USDA Natural Resources Conservation Service, Resource Inventory Division. http://www.nrcs.usda.gov/technical/NRI/ 2003/Landuse-mrb.pdf.

USDA FSA (Farm Service Agency). 2005. Agricultural Resource Conservation Program 2-CRP (Revision 4) Handbook. Washington, DC.

USDA FSA. 2009. The Soils Data Management System. https://arcticocean.sc.egov.usda.gov/soilDbMgnt/ SoilWelcome.do.

USGS (US Geological Survey). 2009. National Hydrography Dataset. http://nhd.usgs.gov/data.html.

USDA NRCS (Natural Resources Conservation Service). 2008. Geospatial Data Gateway. http://datagateway.nrcs. usda.gov.

United Nations Population Division. 2007. United Nations Population Division, World Population Prospects; The 2007 Revision Population Database. Division of the Department of Economic and Social Affairs of the United Nations Secretariat, World Population Prospects: The 2006 Revision and World Urbanization Prospects: The 2007 Revision. http://esa.un.org/unup.

Zhang, N., M. Wang, and N. Wang. 2000. Precision agriculture-a worldwide overview. Computers and Electronics in Agriculture 36:113-132. 